\title{
What's in a jellyfish? Proximate and elemental composition and biometric relationships for use in biogeochemical studies
}

\author{
Ecological Archives E092-144
}

\author{
Cathy H. Lucas, ${ }^{1,6}$ Kylie A. Pitt, ${ }^{2}$ Jennifer E. Purcell, ${ }^{3}$ Mario Lebrato, ${ }^{4}$ and Robert H. Condon ${ }^{5}$ \\ ${ }^{1}$ National Oceanography Centre Southampton, University of Southampton Waterfront Campus, European Way, \\ Southampton SO14 $3 \mathrm{ZH}$ United Kingdom \\ ${ }^{2}$ Australian Rivers Institute and Griffith School of Environment, Griffith University, Queensland 4222 Australia \\ ${ }^{3}$ Shannon Point Marine Center, Western Washington University, 1900 Shannon Point Road, Anacortes, Washington 98221 USA \\ ${ }^{4}$ IFM-GEOMAR, Leibnitz Institute of Marine Science, Department of Marine Biogeochemistry, \\ Düsternbrooker Weg 20, Kiel 24105 Germany \\ ${ }^{5}$ Dauphin Island Sea Lab, Dauphin Island, Alabama 36528 USA
}

\begin{abstract}
Many marine organisms have gelatinous bodies, but the trait is most common in the medusae (phylum Cnidaria), ctenophores (phylum Ctenophora), and the pelagic tunicates (phylum Chordata, class Thaliacea). Although there are taxonomic and trophic differences between the thaliaceans and the other two closely related phyla, the collective term "jellyfish" has been used within the framework of this article. Because of the apparent increase in bloom events, jellyfish are receiving greater attention from the wider marine science community. Questions being posed include: (1) what is the role of jellyfish in pelagic food webs in a changing environment, and (2) what is the role of jellyfish in large-scale biogeochemical processes such as the biological carbon pump? In order to answer such questions, fundamental data on body composition and biomass are required. The purpose of this data set was to compile proximate and elemental body composition and length-mass and mass-mass regressions for jellyfish (i.e., medusae, siphonophores, ctenophores, salps, doliolids, and pyrosomes) to serve as a baseline data set informing studies on biogeochemical cycling, food web dynamics, and ecosystem modeling, as well as physiology. Using mainly published data from 1932 to 2010, we have assembled three data sets: (1) body composition (wet, dry, and ash-free dry mass, C, N, P as a percentage of wet and dry mass, and C:N), (2) length-mass biometric equations, and (3) mass-mass biometric equations. The data sets represent a total of 102 species from six classes (20 Thaliacea, 2 Cubozoa, 33 Hydrozoa, 26 Scyphozoa, 17 Tentaculata, 4 Nuda) in three phyla. Where it exists, we have included supplementary data on location, salinity, whole animal or tissue type, measured size range, and where appropriate, the regression type with values of sample size, correlation coefficients $\left(r, r^{2}\right)$ and level of significance for the relationship. In addition to the raw unpublished data, we have provided summary tables of mean $( \pm \mathrm{SD})$ body composition for the main taxonomic groups.
\end{abstract}

Key words: biometric relationships; carbon; ctenophores; dry mass; medusae; nitrogen; organic mass; proximate composition; salps.

The complete data sets corresponding to abstracts published in the Data Papers section of the journal are published electronically in Ecological Archives at 〈http://esapubs.org/archive〉. (The accession number for each Data Paper is given directly beneath the title.)

Manuscript received 22 February 2011; revised 29 April 2011; accepted 3 May 2011. Corresponding Editor: W. K. Michener.

6E-mail: cathy.lucas@noc.soton.ac.uk 